\title{
Clarity needed on access to COVID vaccine
}

The British Dental Association (BDA)

has welcomed interim advice from the

Joint Committee on Vaccination and

Immunisation (JCVI) recommending health

and social care workers receive priority

access to a coronavirus vaccine, if one is authorised for use in the UK, stressing

there can be no ambiguity over the status of dentists and dental team members in both NHS and private settings.

Failure to provide explicit references to the 'key worker' status of dental professionals caused running issues in terms of access to childcare during lockdown. The recent free NHS flu jab programme, while officially targeted at 'all NHS frontline workers' in England, did not cover dentists or their teams. In an open letter to Secretary of State Matt Hancock (https://bit.ly/36VAlTb), the BDA has sought written assurances that all colleagues will be considered in that priority group.

Chair of the BDA's General Dental

Practice Committee, Dave Cottam said: 'It's है right healthcare workers are being put at the front of the queue for a future COVID vaccine.

'But there can be no repeat of the debacle over flu jabs and "key worker" status.

Dentists - both NHS and private - are frontline health professionals. Together with our teams we need protection so we can keep providing an essential service to the patients that need us.

'The vaccine may still be in development, but clarity on access is needed now.
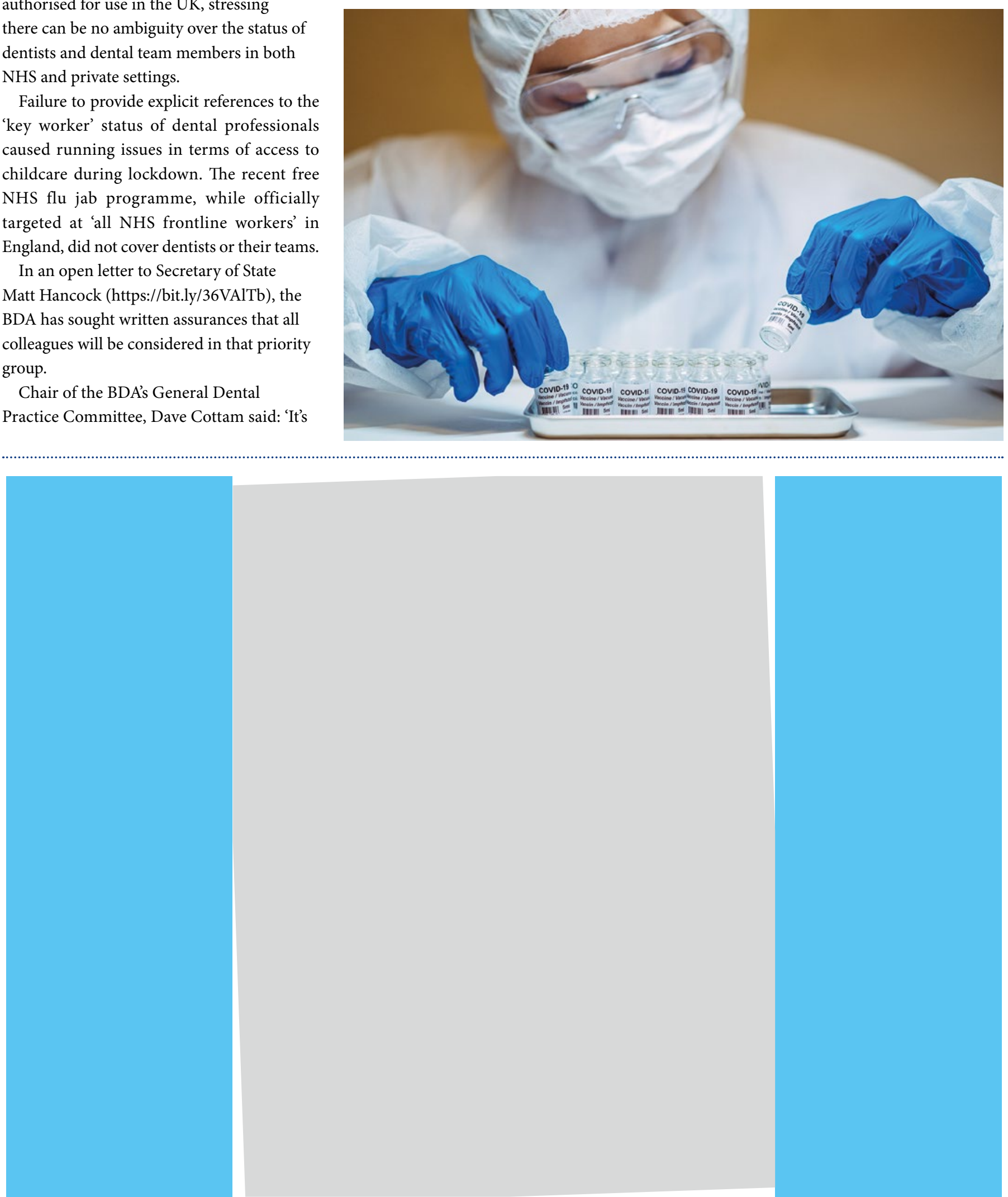